\title{
Absorbing Information about a Child's Incurable Cancer
}

\author{
Patrizia Lannen ${ }^{a, d}$ Joanne Wolfe ${ }^{b, c}$ Jennifer Mack ${ }^{b, c}$ Erik Onelov $^{e}$ \\ Ullakarin Nyberge, ${ }^{e} \quad$ Ulrika Kreicbergs ${ }^{a, f}$ \\ a Phyllis F. Cantor Center and ${ }^{b}$ Department of Psychosocial Oncology and Palliative Care and the Center for \\ Outcomes and Policy Research, Dana-Farber Cancer Institute, and 'Department of Medicine, Children's Hospital, \\ Boston, Mass., USA; ${ }^{d}$ Institute of Social and Preventive Medicine, University of Bern, Bern, Switzerland; ${ }^{e}$ Division \\ of Clinical Cancer Epidemiology, and f Department of Women and Child's Health, Karolinska Institutet, and \\ ${ }^{9}$ Department of Clinical Neuroscience, Karolinska Institutet, St. Goran's Hospital, Stockholm, Sweden
}

\section{Key Words}

Prognostic information - Childhood cancer •

Communication

\begin{abstract}
Purpose: To assess parents' ability to absorb information that their child's cancer was incurable and to identify factors associated with parents' ability to absorb this information. Patients and Methods: An anonymous mail-in questionnaire study was performed as a population-based investigation in Sweden between August and October of 2001. 449 parents who lost a child to cancer 4-9 years earlier (response rate $80 \%$ ) completed the survey. 191 (43\%) of the bereaved parents were fathers and 251 (56\%) were mothers. Results: Sixty percent of parents $(n=258)$ reported that they were able to absorb the information that their child's illness was incurable. Parents were better able to absorb this information when the information was given in an appropriate manner (RR 1.6; Cl 1.3-2.0), when they shared their problems with others during the child's illness course (RR $1.4 ; \mathrm{Cl} 1.1-1.8)$ and when they had no history of depression (RR 1.3; $\mathrm{Cl} 1.0-1.8$ ). Parents who reported that they were able to absorb the information were more likely to have expressed their farewells to the child in their desired manner (RR 1.3; Cl 1.0-1.5). Conclusions: Parents who received information that their child's
\end{abstract}

illness was incurable in an appropriate manner are more likely to absorb that information. Whether or not parents are able to absorb the information that their child's cancer is incurable has implications in terms of preparation for the child's impending death.

Copyright ๑ 2010 S. Karger AG, Basel

\section{Introduction}

When a child reaches the point that his or her cancer is incurable, parents have most likely gone through a number of challenging conversations with the medical team. Such conversations likely occurred at diagnosis of their child's cancer, at recurrences, and when the goal of care shifts from curative to palliative care.

Interestingly, there is substantial variability in how well parents are informed throughout the different stages of their child's illness. Patients and families feel better

Studies originating from the same data set have been published in The Lancet (2004), Psychological Medicine (2004), The New England Journal of Medicine (2004), Pediatrics (2006), Palliative Medicine (2006), Journal of Palliative Medicine (2006), Journal of Clinical Oncology $(2005,2007,2008)$, Acta Oncologica and Lancet Oncology (2007).

\section{KARGER}

() 2010 S. Karger AG, Basel

Fax +41613061234

E-Mail karger@karger.ch

www.karger.com
Accessible online at: www.karger.com/ocl
Ulrika Kreicbergs

Department of Women and Child's Health Q6:05

Karolinska Institutet

SE-171 76 Stockholm (Sweden)

Tel. +4685248 8410, Fax +4685177 9621, E-Mail ulrika.kreicbergs@ki.se 
informed at the beginning of the illness, and they experience more uncertainty as the illness progresses [1-5]. In fact, Wolfe et al. [4] found fairly high concordance between parents' and physicians' beliefs about the likelihood of cure at diagnosis. As the child's condition deteriorated, however, parents' understanding and/or acceptance that their child did not have a realistic chance of cure was substantially delayed.

Parents' perception of insufficient and uncaring delivery of information by health care professionals was associated with lingering regret [6] and emotional distress [7, 8]. Several studies have revealed the importance parents place on clear, understandable and complete information about their child's condition [3, 5, 9-12]. For example, parents rate the quality of care higher when they feel that clear information was given about what to expect during end-of-life care [13].

The importance of clear information about the child's condition is further highlighted by findings suggesting that parental understanding of the child's condition and prognosis may also play an important role in their endof-life decision-making process [4]. For example, Wolfe et al. [4] found that elements of palliative care were more likely to be integrated into the child's care when both the physicians and parents recognized earlier on that the child had no realistic chance of cure and that both parents and physicians shared the common goal of lessening the suffering of the child.

Even if parents are given information about the condition and prognosis of their child, it is unclear whether and under what circumstances they are able to actually absorb the information provided.

In this study we examined how, when, and from whom mothers and fathers of a child with cancer reported having received information about their child's terminal condition. Furthermore, we identified factors associated with parental ability to absorb this information. Finally, we explored outcomes associated with mothers and fathers being able to absorb the information that their child's cancer was incurable.

\section{Methods}

\section{Study Design}

368 children diagnosed with cancer prior to the age of 17 and deceased before the age of 25 between 1992 and 1997 in Sweden were identified by means of the Swedish Cause of Death Registry and the Swedish Cancer Registry and their parents through the Swedish Population Registry. To be eligible, parents needed to be the guardian of the child at the time of diagnosis, have a listed phone number, be born in any of the Nordic countries, and speak Swedish. 561 parents were determined eligible. The diagnosis of the child was verified, and the child's former physician was asked for permission to contact each parent. Permission to contact all parents was given.

\section{Data Collection}

In order to recruit the parents, a letter of introduction inviting them to participate and explaining the purpose of the study was sent to each parent between August and October of 2001. Ten days later, the parents received a phone call and were asked whether they would like to participate. If they agreed, an anonymous, mail-in questionnaire, as well as a response card, were sent to them. The parents were asked to return the response card separately from the questionnaire as a way of maintaining anonymity and keeping track of who had returned the questionnaire. Ten days after the questionnaire was sent out, a card was sent to each parent thanking them for participating and at the same time reminding those parents who had not yet returned the questionnaire to do so. The parents who still had not returned the questionnaire another 10 days later were called by an interviewer and offered assistance in filling out the questionnaire if necessary.

\section{Instrument Development}

In order to develop the questionnaire, interviews with parents who had lost a child to cancer as well as discussions with health care professionals were performed to elicit relevant themes. Questions were constructed related to the different themes. The final version of the questionnaire included 129 questions with a total of 365 items.

The questionnaire was tested face-to-face in order to assure correct understanding of all questions. As a last preparatory step, a pilot study was performed to evaluate participation rate, internal loss to follow-up, and study logistics.

The questions covered aspects of information from the time of diagnosis, at possible recurrence, and when the child's illness had reached incurability.

Parents were asked whether they had been able to absorb the information that their child's illness was incurable. Response options included: (1) not relevant, I never received such information; (2) no, not at all; (3) to a certain extent; (4) yes, for the most part; (5) yes, completely. All variables associated with 'absorption of information' were also asked as single-item questions.

In addition, parents were asked about their marital status, age, sex, number of children, education, employment status, and region of residence.

\section{Analysis}

Statistics were produced using SPSS version 15. We reported information variables as proportions for mothers and fathers separately, as well as in combination; $p$ values for the differences between mothers and fathers were computed using the $\chi^{2}$ statistic. We dichotomized the question 'absorption of information', collapsing 'no, not at all' and 'to a certain extent' and collapsing 'yes, for the most part' and 'yes, completely' and calculated proportions of each independent variable for the bivariable categories. To compare categories we calculated the relative risk as the ratio of proportions, together with the $95 \%$ confidence interval. The $\mathrm{p}$ values for univariate associations were calculated using the Fisher 
Exact (two-sided) statistic for bivariate analyses and $\chi^{2}$ when there were more than two response categories.

Multivariable binary logistic models were then constructed to determine the relative importance of the independent variables in order to explain the variation in the outcome. Those parents who stated that they did not receive such information were excluded. For selection of variables we used both forward selection and backward elimination.

The entire study was approved by the Regional Ethics Committee of the Karolinska Institutet.

\section{Results}

Characteristics of participating parents are shown in table 1 .

\section{Receipt of Information}

Table 2 summarizes from whom and when parents received information about diagnosis, recurrence, and incurability of their child's illness, as well as whether they thought the information was given in an appropriate manner. About half of the parents received the information regarding the child's diagnosis when the child was present, and around 30\% of the parents reported that the child was present when they received the information that his or her illness was incurable. Furthermore, around $60 \%$ of parents reported that they were informed about the incurability of their child's illness in an appropriate manner (either yes, entirely; or yes, for the most part).

$201(86 \%)$ mothers and 163 (88\%) fathers reported that they wanted the information on incurability from the physician immediately once their child's illness was regarded as incurable.

\section{Absorption of Information about Incurability}

Thirty-seven (9\%) parents reported that they were 'not at all' able to absorb the information that their child's cancer was incurable, $83(20 \%)$ were able to absorb it 'to a certain extent', 141 (33\%) 'for the most part' and 117 (27\%) 'completely'. Fifty-one (12\%) parents stated that they never received such information.

Table 3 displays variables associated with parents' ability to absorb information regarding their child's illness being incurable. Parents with no history of depression, those who reported that they shared their problems with others during the child's illness, and those who thought that the information was given in an appropriate manner were more likely to have absorbed the information given.

Absorbing Information about a Child's Incurable Cancer
Table 1. Characteristics of the parents studied who had lost a child to cancer 4-9 years earlier

\begin{tabular}{|c|c|}
\hline Characteristics & $\begin{array}{l}\text { Bereaved } \\
\text { parents, } n\end{array}$ \\
\hline Identified as eligible in registries & 561 \\
\hline \multicolumn{2}{|l|}{ Reasons for not responding } \\
\hline Refused to participate & $30(5 \%)$ \\
\hline Agreed but did not participate & $59(11 \%)$ \\
\hline Could not be contacted & $23(4 \%)$ \\
\hline Total nonresponders & $112(20 \%)$ \\
\hline Participating parents & $449(80 \%)$ \\
\hline Biological parent & $438(98 \%)$ \\
\hline Non-biological parent & $9(2 \%)$ \\
\hline Not stated & $2(<1 \%)$ \\
\hline \multirow{3}{*}{$\begin{aligned} \text { Gender } & \text { Male } \\
& \text { Female } \\
& \text { Not stated }\end{aligned}$} & $191(43 \%)$ \\
\hline & $251(56 \%)$ \\
\hline & $7(2 \%)$ \\
\hline \multirow{4}{*}{$\begin{array}{l}<30 \text { years } \\
30-39 \text { years } \\
40 \text { years or older } \\
\text { Not stated }\end{array}$} & $66(15 \%)$ \\
\hline & $232(52 \%)$ \\
\hline & $146(32 \%)$ \\
\hline & $5(1 \%)$ \\
\hline \multicolumn{2}{|l|}{ Marital status today } \\
\hline Married or living with the child's other parent & $329(73 \%)$ \\
\hline Married or living with another partner & $51(11 \%)$ \\
\hline Has a partner but lives alone & $17(4 \%)$ \\
\hline Single & $45(10 \%)$ \\
\hline Not stated & $7(2 \%)$ \\
\hline \multicolumn{2}{|l|}{ Number of children at child's diagnosis } \\
\hline 1 & $82(18 \%)$ \\
\hline 2 & $192(43 \%)$ \\
\hline 3 & $116(26 \%)$ \\
\hline 4 or more & $54(12 \%)$ \\
\hline Not stated & $5(1 \%)$ \\
\hline \multicolumn{2}{|l|}{ Level of education } \\
\hline Elementary school & $83(18 \%)$ \\
\hline Secondary school & $215(48 \%)$ \\
\hline University & $141(31 \%)$ \\
\hline Not stated & $10(2 \%)$ \\
\hline \multicolumn{2}{|l|}{ Employment status } \\
\hline Employed & $370(82 \%)$ \\
\hline Unemployed & $10(2 \%)$ \\
\hline On sick leave/retired & $36(8 \%)$ \\
\hline Housewife/husband & $5(1 \%)$ \\
\hline Home with children & $8(2 \%)$ \\
\hline Student & $14(3 \%)$ \\
\hline Not stated & $6(1 \%)$ \\
\hline \multicolumn{2}{|l|}{ Region of residence } \\
\hline Rural & $99(22 \%)$ \\
\hline Village/town & $273(61 \%)$ \\
\hline Large city $(>500,000$ inhabitants $)$ & $68(15 \%)$ \\
\hline Not stated & $9(2 \%)$ \\
\hline \multicolumn{2}{|l|}{ Religiousness } \\
\hline Not religious at all & $185(41 \%)$ \\
\hline Somewhat religious & $155(35 \%)$ \\
\hline Quite religious & $68(15 \%)$ \\
\hline Very religious & $25(6 \%)$ \\
\hline Not stated & $16(4 \%)$ \\
\hline
\end{tabular}

Oncology 2010;78:259-266 
Table 2. Characteristics of how parents received information about their child's illness ${ }^{1}$

\begin{tabular}{|c|c|c|c|}
\hline & Fathers $(\mathrm{n}=191)$ & Mothers $(n=251)$ & Total $(\mathrm{n}=442)$ \\
\hline \multicolumn{4}{|c|}{ How did you get the information that your child had cancer? } \\
\hline N/A; I never got such information & $1(0.5)$ & $3(1.2)$ & $4(0.99)$ \\
\hline With physician, child and other parent present & $78(40.85)$ & $82(32.7)$ & $160(36.2)$ \\
\hline With physician and other parent present & $53(27.8)$ & $63(25.1)$ & $116(26.2)$ \\
\hline With physician and child present & $12(6.3)$ & $36(14.3)$ & $48(10.9)$ \\
\hline With physician & $5(2.6)$ & $36(14.3)$ & $41(9.3)$ \\
\hline From other parent & $23(12.0)$ & $9(3.6)$ & $32(7.2)$ \\
\hline From child & $1(0.5)$ & $0(0)$ & $1(0.2)$ \\
\hline Via telephone & $12(6.3)$ & $14(5.6)$ & $26(5.9)$ \\
\hline Other & $3(1.6)$ & $6(2.4)$ & $9(2.0)$ \\
\hline Missing & $3(1.6)$ & $2(0.8)$ & $5(1.1)$ \\
\hline \multicolumn{4}{|c|}{ How did you get the information that your child's illness had recurred the first time? } \\
\hline N/A; the illness never recurred & $20(10.5)$ & $40(15.9)$ & $60(13.6)$ \\
\hline With physician, child and other parent present & $47(24.6)$ & $50(19.9)$ & $97(21.9)$ \\
\hline With physician and other parent present & $24(12.6)$ & $28(11.1)$ & $52(11.8)$ \\
\hline With physician and child present & $11(5.8)$ & $28(11.2)$ & $39(8.8)$ \\
\hline With physician & $4(2.1)$ & $15(6.0)$ & $19(4.3)$ \\
\hline From other parent & $15(7.8)$ & $8(3.2)$ & $23(5.2)$ \\
\hline From child & $1(0.5)$ & $0(0)$ & $1(0.2)$ \\
\hline Via telephone & $13(6.8)$ & $16(6.4)$ & $29(6.6)$ \\
\hline Other & $9(4.7)$ & $17(6.8)$ & $26(7.5)$ \\
\hline Missing & $47(24.6)$ & $49(19.5)$ & $96(21.7)$ \\
\hline \multicolumn{4}{|c|}{ Was the information that your child's illness had recurred given in what you consider to be an appropriate manner? } \\
\hline $\mathrm{N} / \mathrm{A}$; the illness never recurred & $21(10.9)$ & $42(16.7)$ & $63(14.2)$ \\
\hline No, not at all & $10(5.2)$ & $18(7.2)$ & $28(6.3)$ \\
\hline To a certain extent & $21(11)$ & $18(7.2)$ & $39(8.8)$ \\
\hline Yes, for the most part & $49(25.6)$ & $62(24.7)$ & $111(25.1)$ \\
\hline Yes, entirely & $37(19.4)$ & $54(21.5)$ & $91(20.6)$ \\
\hline Missing & $53(11.8)$ & $57(12.9)$ & $110(24.9)$ \\
\hline \multicolumn{4}{|c|}{ How did you get the information that your child's illness was incurable? } \\
\hline N/A; I never got such information & $27(14.1)$ & $35(13.9)$ & $62(13.8)$ \\
\hline With physician, child and other parent present & $52(27.2)$ & $55(21.9)$ & $107(24.2)$ \\
\hline With physician and other parent present & $75(39.3)$ & $97(38.6)$ & $172(38.9)$ \\
\hline With physician and child present & $7(3.7)$ & $15(6.0)$ & $22(4.8)$ \\
\hline With physician & $8(4.2)$ & $28(11.2)$ & $36(8.1)$ \\
\hline From other parent & $4(2.1)$ & $5(2.0)$ & $9(2.0)$ \\
\hline Via telephone & $6(3.1)$ & $6(2.4)$ & $12(2.7)$ \\
\hline By letter & $1(0.5)$ & $1(0.4)$ & $2(0.5)$ \\
\hline Other & $4(2.1)$ & $4(1.6)$ & $8(1.8)$ \\
\hline Missing & $7(3.7)$ & $5(2.0)$ & $12(2.7)$ \\
\hline \multicolumn{4}{|c|}{ When did you get the information that your child's illness was incurable? } \\
\hline N/A; I never got such information & $23(12.0)$ & $28(11.1)$ & $51(11.5)$ \\
\hline Within $24 \mathrm{~h}$ before he/she died & $12(6.3)$ & $19(7.6)$ & $31(7.0)$ \\
\hline A few days before he/she died & $6(3.1)$ & $13(5.2)$ & $19(4.3)$ \\
\hline A week before he/she died & $8(4.2)$ & $12(4.8)$ & $20(4.5)$ \\
\hline 2-4 weeks before he/she died & $25(13.1)$ & $25(10.0)$ & $50(11.3)$ \\
\hline $1-3$ months before he/she died & $55(28.8)$ & $69(27.5)$ & $124(28.1)$ \\
\hline 4-6 months before he/she died & $33(17.3)$ & $41(16.3)$ & $74(16.7)$ \\
\hline 7-11 months before he/she died & $13(6.8)$ & $17(6.8)$ & $30(6.8)$ \\
\hline 1 year before he/she died & $3(1.6)$ & $11(4.4)$ & $14(3.2)$ \\
\hline 2 years or longer before he/she died & $6(3.1)$ & $10(4.0)$ & $16(3.6)$ \\
\hline Missing & $7(3.7)$ & $6(2.4)$ & $13(2.9)$ \\
\hline
\end{tabular}


Table 2 (continued)

$$
\text { Fathers }(\mathrm{n}=191) \quad \text { Mothers }(\mathrm{n}=251) \quad \text { Total }(\mathrm{n}=442)
$$

Was the information that your child's illness was incurable given in what you consider to be an appropriate
manner?
N/A; I never got such information

\footnotetext{
${ }^{1}$ Seven parents did not state their gender, therefore we can only present data on 442 parents by gender. Figures in parentheses are percentages.
}

In multivariate modeling of factors associated with parents' ability to absorb information about the child's incurable cancer most of the variance was explained by whether the information was given in an appropriate manner $(\mathrm{p}<$ $0.001)$, when the curative treatment ended $(p=0.045)$, and whether the parents had someone to share their problems with during the child's illness ( $\mathrm{p}=0.051$, table 4$)$.

\section{Outcomes Associated with Absorbing Information about Incurability}

Parents who reported having absorbed the information that their child's cancer was incurable were more likely to have expressed their farewells to the child in the way that they wanted to (RR 1.3; CI 1.0-1.5). No significant results were found when looking at where the child died and its association with whether or not parents had absorbed the information about their child's incurability.

\section{Discussion}

Communication and specifically the provision of information is one of the most important aspects of professional care-taking. The manner in which information about incurability is delivered in end-of-life communication has great implications on how patients and family caregivers experience quality of care [14-16]. To our knowledge, no previous studies have addressed parents' ability to absorb information about the child's cancer being incurable. In our study, over $50 \%$ of parents were unable to fully absorb information regarding their child's incurability. However, absorption of this information was more likely if parents perceived that it was given in an appropriate manner. Thus, the quality of physician communication may substantially impact parents' ability to 'hear' news that understandably is so difficult to bear.

About half of the parents reported that information about recurrence as well as incurability of the child's illness was given in an appropriate manner. Our data does not allow us to determine which factors hinder communicating appropriately, however, other studies suggest possible explanations. An important contributing factor may be related to the limited training of physicians in the area of communication [17]. Physicians may also wonder whether discussing prognostic information is the right thing to do [18-20] and assume that discussing difficult aspects of the illness may not meet the parents' needs $[4,21]$. They may also worry that it may upset patients [19, 22-25], or take away hope [24-31]. However, in a study by Mack et al. [11], it was shown that parents of pediatric cancer patients do want detailed prognostic information about their child's illness, even if the information is emotionally upsetting. Furthermore, they found that discussing prognostic information does not take away hope [11]. All in all, these results emphasize the critical importance of physician education about communication in order to enable parents to absorb distressing information. It also highlights the significance of implementing communication guidelines [11, 32, 33] in clinical practice.

Being informed without delay about the child's terminal condition may provide an opportunity for the parents to make end-of-life decisions according to their traditions and values and prepare for the child's impeding death, preparations which have been shown to be beneficial to bereaved parents in the long term $[34,35]$. 
Table 3. Variables associated with parents' ability to absorb information regarding their child's disease being incurable

\begin{tabular}{|c|c|c|c|c|}
\hline & $\begin{array}{l}\text { Parent able to } \\
\text { absorb information }\end{array}$ & $\mathrm{RR}$ & $\mathrm{CI}$ & $\begin{array}{l}\mathrm{p} \text { value } \\
\left(\chi^{2} / \text { Fisher }\right)\end{array}$ \\
\hline \multicolumn{5}{|c|}{ How did you receive the information that your child's illness was incurable? } \\
\hline Physician & $227 / 332(68)$ & 1.3 & $1.0-1.6$ & \\
\hline Info from other & $17 / 26(65)$ & 1.0 & ref. & 0.828 \\
\hline \multicolumn{5}{|l|}{ Anxiety the year before your child's diagnosis } \\
\hline No & $226 / 323(70)$ & 1.2 & $0.9-1.6$ & \\
\hline Yes & $25 / 43(58)$ & 1.0 & ref. & 0.120 \\
\hline \multicolumn{5}{|c|}{ Depression the year before your child's diagnosis } \\
\hline No & $227 / 323(70)$ & 1.3 & $1.0-1.8$ & \\
\hline Yes & $23 / 43(53)$ & 1.0 & ref. & 0.035 \\
\hline \multicolumn{5}{|l|}{ Marital status at child's diagnosis } \\
\hline Married/cohabited with other parent & $225 / 329(68)$ & 1.0 & ref. & \\
\hline Married/cohabited with other & $6 / 11(55)$ & 0.8 & $0.5-1.4$ & \\
\hline In a relationship & $5 / 9(56)$ & 0.8 & $0.5-1.5$ & \\
\hline Single & $17 / 23(74)$ & 1.1 & $0.8-1.4$ & 0.583 \\
\hline \multicolumn{5}{|l|}{ Duration of illness } \\
\hline$<1$ year & $90 / 127(71)$ & 1.1 & $0.9-1.3$ & \\
\hline$>1$ year & $156 / 239(67)$ & 1.0 & ref. & 0.295 \\
\hline \multicolumn{5}{|l|}{ Type of cancer } \\
\hline Brain tumor & $95 / 143(66)$ & 1.0 & ref. & \\
\hline Leukemia & $77 / 109(71)$ & 1.1 & $0.9-1.3$ & \\
\hline Sarcoma & $61 / 87(70)$ & 1.1 & $0.9-1.3$ & \\
\hline Other & $21 / 34(62)$ & 0.9 & $0.7-1.2$ & 0.730 \\
\hline \multicolumn{5}{|c|}{ Was the information that your child's illness was incurable given in what you consider to be an appropriate manner? } \\
\hline Yes & $201 / 258(78)$ & 1.6 & $1.3-2.0$ & \\
\hline No & $53 / 110(48)$ & 1.0 & ref. & $<0.001$ \\
\hline \multicolumn{5}{|c|}{ When did your child's curative treatment cease? } \\
\hline Last days & $80 / 109(73)$ & 1.3 & $1.0-1.5^{*}$ & \\
\hline Week-3 months & $120 / 174(69)$ & 1.2 & $1.0-1.4$ & \\
\hline 4 months-more than 3 years & $50 / 85(59)$ & 1.0 & ref. & 0.090 \\
\hline \multicolumn{5}{|c|}{ Parent had someone to share their own problems with during the child's illness } \\
\hline Most to all & $138 / 190(73)$ & 1.4 & $1.1-1.8$ & \\
\hline Less or more than half & $83 / 122(68)$ & 1.3 & $1.0-1.7$ & \\
\hline None or almost none & $29 / 56(52)$ & 1.0 & ref. & 0.013 \\
\hline \multicolumn{5}{|c|}{ When did you receive information that your child's illness was incurable? } \\
\hline Last week & $45 / 69(65)$ & 1.0 & $0.8-1.2$ & \\
\hline 2 weeks -3 months & $122 / 170(72)$ & 1.1 & $0.9-1.3$ & \\
\hline 4 months-more than 2 years & $86 / 132(65)$ & 1.0 & ref. & 0.398 \\
\hline
\end{tabular}

Table 4. Multivariable logistic regression (forward selection ${ }^{1}$ ) for when information was absorbed that the child's illness was incurable

\begin{tabular}{|c|c|c|c|c|}
\hline Variable & Nagelkerke's $\mathrm{R}^{2}$ & $\chi^{2}$ & d.f. & $\mathrm{p}$ \\
\hline Intercept and information was given in an appropriate manner & 0.12 & 28,989 & 1 & $<0.001$ \\
\hline When the curative treatment ended & 0.14 & 6,569 & 2 & 0.037 \\
\hline $\begin{array}{l}\text { Whether the parents had someone to share their problems with during the } \\
\text { child's illness }\end{array}$ & 0.16 & 5,874 & 2 & 0.053 \\
\hline
\end{tabular}

Step 1: appropriate; step 2: appropriate, treatment ceased; step 3: appropriate, treatment ceased and share problems.

${ }^{1}$ Please note that results were confirmed by applying backward elimination. 
Eighty-six percent of mothers and $88 \%$ of fathers wanted the physician to let them know immediately when the illness was incurable. This result is consistent with previous findings from another study, which indicated that parents prefer receiving this information as early as possible [10]. Importantly, we found that parents who grasped the information that their child's illness was incurable were more likely to express their farewells before the child died.

In addition, parents who reported that they shared their problems with others during the child's illness were more likely to absorb the information about the child's incurability. It is reasonable to think that sharing problems with others may be a way to process the information and increase the chance that the information sinks in.

We found wide variability in the specific manner in which information about the child was given throughout the course of illness. Parents reported, for example, that the more severe the child's illness, the more likely it was that fathers also received the information directly from the physician, rather than through other channels. We also found that the more severe the illness, the less often the child was present during information giving by the physician. Fifty-seven percent of the parents reported that the child was present during the conversation with the physician about diagnosis, while only $39 \%$ reported that the child was present during information about recurrence and $30 \%$ when incurability was being discussed. There are studies indicating that the presence of the child, especially older children and teenagers, might be beneficial when prognostic information is being discussed [16]. Otherwise, young people may assume that the information they received was not completely honest [16]. Mack et al. [11] showed that parents were less upset when their child was present during prognostic discussion than when they were absent. This may raise the question whether prognostic discussions are more optimistic when the child is present and therefore less upsetting to parents. But this was not supported in the study. Parents were also likely to rate quality of physician care high when physicians communicated directly with the child as long as parents thought that the child was old enough [13].

Jedlicka-Köhler et al. [36] conducted a study involving 46 parents who received information about their child's diagnosis of cystic fibrosis by the child's pediatrician and found great variability in the amount of information the parents were able to retain. Thirty-three percent of these parents reported that they retained $50 \%$ or less of the information given to them [36]. The number of parents in our study reporting that they had significant difficulties absorbing the information they received (29\% of parents reporting that they were not at all or only to a certain extent able to absorb the information that their child's illness was incurable) even exceeds those numbers. This may be explained by the increased severity of the situation. Jedlicka-Köhler et al. [36] suggested as an explanation for the reduced retention that the parents' memory was disturbed by the presence of negative emotions and base their conclusion on findings of other research groups that found that powerful negative emotions can disturb memory [37]. They also conclude that depressed individuals may select and process information in a way that is consistent with their present mood state, while ignoring information that would provide a more accurate picture [38]. Though a history of depression was associated with less absorption of information about the child's incurability in our study, we do not know whether the parent was actually depressed at the time of receiving the information. Future studies should further evaluate the role of parent affect and ability to absorb distressing information.

In addition, our study found that parents of children whose curative treatment ended closer to the time of death were more likely to absorb information about the incurability of the child's disease. Additional research is necessary to better understand the implications of this finding.

This nationwide study has a high participation rate of $80 \%$, which reduces the risk of participation bias. It also included similar numbers of mothers and fathers. Still, there are several limitations. First, it is a cross-sectional study that relies on parents reporting on issues in the past. One may wonder what parents mean when reporting that information was given in an 'appropriate' manner. Still, we believe that the parents are the only ones that can truly judge whether information was given in an appropriate way in their eyes. For future advancement of care, it is important to understand parents' perception of what is an appropriate way of delivering such sensitive information.

In summary, the findings that information given in an appropriate manner increases parents' ability to absorb the information about their child's illness being incurable is valuable for clinical practice. It supports the need for education and training for health care professionals to deliver bad news in a way that enhances understanding of the news itself. Furthermore, absorption of information has critical clinical implications for the parental preparation of their child's death. Health care profession- 
als may use the findings of this study to identify parents at risk for difficulties absorbing challenging medical information and can encourage parents to discuss problems with others as an opportunity to process information throughout the child's illness.

\section{Acknowledgments}

We thank the parents who made this study possible by bravely sharing their experiences with us. The study was supported by grants from the Swedish Children's Cancer Foundation, the Swedish Society for Medical Research, the Swiss Cancer League (KLS-01645-02-2005), the National Cancer Institute (No. NCI 5 K07 CA 096746), and the American Cancer Society.

\section{References}

1 Friedrichsen MJ, Strang PM: Doctors'strategies when breaking bad news to terminally ill patients. J Palliat Med 2003;6:565-574.

$\checkmark 2$ Hoff L, Tidefelt U, Thaning L, Hermeren G: In the shadow of bad news - views of patients with acute leukaemia, myeloma or lung cancer about information, from diagnosis to cure or death. BMC Palliat Care 2007;6:1.

-3 Meyer EC, Ritholz MD, Burns JP, Truog RD: Improving the quality of end-of-life care in the pediatric intensive care unit: parents' priorities and recommendations. Pediatrics 2006;117:649-657.

4 Wolfe J, Klar N, Grier HE, Duncan J, SalemSchatz S, Emanuel EJ, Weeks JC: Understanding of prognosis among parents of children who died of cancer: impact on treatment goals and integration of palliative care. JAMA 2000;284:2469-2475.

5 Curley MA: Effects of the nursing mutual participation model of care on parental stress in the pediatric intensive care unit. Heart Lung 1988;17:682-688.

-6 Meyer EC, Burns JP, Griffith JL, Truog RD: Parental perspectives on end-of-life care in the pediatric intensive care unit. Crit Care Med 2002;30:226-231.

7 Contro N, Larson J, Scofield S, Sourkes B, Cohen H: Family perspectives on the quality of pediatric palliative care. Arch Pediatr Adolesc Med 2002;156:14-19.

-8 Contro NA, Larson J, Scofield S, Sourkes B, Cohen HJ: Hospital staff and family perspectives regarding quality of pediatric palliative care. Pediatrics 2004;114:1248-1252.

$\checkmark 9$ Hinds PS, Drew D, Oakes LL, Fouladi M, Spunt SL, Church C, Furman WL: End-oflife care preferences of pediatric patients with cancer. J Clin Oncol 2005;23:91469154.

10 Krahn GL, Hallum A, Kime C: Are there good ways to give 'bad news'? Pediatrics 1993;91:578-582.

-11 Mack JW, Wolfe J, Grier HE, Cleary PD, Weeks JC: Communication about prognosis between parents and physicians of children with cancer: parent preferences and the impact of prognostic information. J Clin Oncol 2006;24:5265-5270.

12 Meert KL, Thurston CS, Sarnaik AP: End-oflife decision-making and satisfaction with care: parental perspectives. Pediatr Crit Care Med 2000;1:179-185.

\section{Mack JW, Hilden JM, Watterson J, Moore C, 27 Turner B, Grier HE, Weeks JC, Wolfe J: Par- ent and physician perspectives on quality of care at the end of life in children with cancer. J Clin Oncol 2005;23:9155-9161.}

14 Steinhauser KE, Christakis NA, Clipp EC McNeilly M, McIntyre L, Tulsky JA: Factors considered important at the end of life by patients, family, physicians, and other care providers. JAMA 2000;284:2476-2482.

15 Kuttner L: Talking to families when their children are dying. Med Princ Pract 2007;16: $16-20$.

16 Mack JW, Grier HE: The day one talk. J Clin Oncol 2004;22:563-566.

17 Hilden JM, Watterson J, Chrastek J: Tell the children. J Clin Oncol 2003;21:37s-39s.

$\checkmark 18$ Christakis NA, Iwashyna TJ: Attitude and self-reported practice regarding prognostication in a national sample of internists. Arch Intern Med 1998;158:2389-2395.

19 Gordon EJ, Daugherty CK: 'Hitting you over the head': oncologists' disclosure of prognosis to advanced cancer patients. Bioethics 2003;17:142-168.

20 Helft PR: Necessary collusion: prognostic communication with advanced cancer patients. J Clin Oncol 2005;23:3146-3150.

21 Weeks JC, Cook EF, O’Day SJ, Peterson LM, Wenger N, Reding D, Harrell FE, Kussin P, Dawson NV, Connors AF Jr, Lynn J, Phillips RS: Relationship between cancer patients predictions of prognosis and their treatment preferences. JAMA 1998;279:1709-1714.

22 Buckman R: How to Break Bad News. Baltimore, Johns Hopkins University Press, 1992.

23 Holland JC, Geary N, Marchini A, Tross S: An international survey of physician attitudes and practice in regard to revealing the diagnosis of cancer. Cancer Invest 1987;5: 151-154.

24 Miyaji NT: The power of compassion: truthtelling among American doctors in the care of dying patients. Soc Sci Med 1993;36:249264.

25 The AM, Hak T, Koeter G, van Der Wal G: Collusion in doctor-patient communication about imminent death: an ethnographic study. BMJ 2000;321:1376-1381.

26 Back AL, Arnold RM, Quill TE: Hope for the best, and prepare for the worst. Ann Intern Med 2003;138:439-443.
7 Baile WF, Lenzi R, Parker PA, Buckman R, Cohen L: Oncologists' attitudes toward and practices in giving bad news: an exploratory study. J Clin Oncol 2002;20:2189-2196.

-28 Clayton JM, Butow PN, Arnold RM, Tattersall $\mathrm{MH}$ : Fostering coping and nurturing hope when discussing the future with terminally ill cancer patients and their caregivers. Cancer 2005;103:1965-1975.

-29 Delvecchio Good MJ, Good BJ, Schaffer C, Lind SE: American oncology and the discourse on hope. Cult Med Psychiatry 1990; 14:59-79.

30 Kodish E, Post SG: Oncology and hope. J Clin Oncol 1995;13:1817.

31 Ruddick W: Hope and deception. Bioethics 1999;13:343-357.

32 Hurwitz CA, Duncan J, Wolfe J: Caring for the child with cancer at the close of life: 'There are people who make it, and I'm hoping I'm one of them'. JAMA 2004;292:21412149.

33 Masera G, Spinetta JJ, Jankovic M, Ablin AR, D’Angio GJ, Van Dongen-Melman J, Eden T, Martins AG, Mulhern RK, Oppenheim D, Topf R, Chesler MA: Guidelines for assistance to terminally ill children with cancer: a report of the SIOP Working Committee on psychosocial issues in pediatric oncology. Med Pediatr Oncol 1999;32:44-48.

34 Kreicbergs UC, Lannen P, Onelov E, Wolfe J: Parental grief after losing a child to cancer: impact of professional and social support on long-term outcomes. J Clin Oncol 2007;25: 3307-3312.

35 Valdimarsdóttir U, Kreicbergs U, Hauksdóttir A, Hunt H, Onelöv E, Henter JI, Steineck G: Parents' intellectual and emotional awareness of their child's impending death to cancer: a population-based long-term follow-up study. Lancet Oncol 2007;8:706-714.

36 Jedlicka-Köhler I, Götz M, Eichler I: Parents' recollection of the initial communication of the diagnosis of cystic fibrosis. Pediatrics 1996;97:204-209.

37 Loftus EF, Burns TE: Mental shock can produce retrograde amnesia. Mem Cognit 1982; 10:318-323.

38 Ottaviani R, Beck AT: Cognitive theory and depression; in Fiedler K, Forgas J (eds): Affect, Cognition and Social Behavior. Toronto, Hogrefe, 1988, pp 209-218. 